Article

\title{
Identification of Cardiac Glycosides as Novel Inhibitors of eIF4A1-Mediated Translation in Triple-Negative Breast Cancer Cells
}

\author{
Cory M. Howard ${ }^{1}\left(\mathbb{D}\right.$, Matthew Estrada ${ }^{1}$, David Terrero ${ }^{2}$, Amit K. Tiwari ${ }^{2}{ }^{(D)}$ and \\ Dayanidhi Raman $1, *(D)$ \\ 1 Department of Cancer Biology, University of Toledo Health Science Campus, Toledo, OH 43614, USA; \\ cory.howard@rockets.utoledo.edu (C.M.H.); estrada.78@buckeyemail.osu.edu (M.E.) \\ 2 Department of Pharmacology \& Experimental Therapeutics, College of Pharmacy \& Pharmaceutical \\ Sciences, University of Toledo Main Campus, Toledo, OH 43606, USA; \\ davidalejandro.terrerorodriguez@rockets.utoledo.edu (D.T.); amit.tiwari@utoledo.edu (A.K.T.) \\ * Correspondence: dayanidhi.raman@utoledo.edu
}

Received: 30 June 2020; Accepted: 2 August 2020; Published: 4 August 2020

\begin{abstract}
The eukaryotic translation initiation factor $4 \mathrm{~F}$ complex (eIF4F) is a potential chemotherapeutic target in triple-negative breast cancer (TNBC). This complex regulates cap-dependent translational initiation and consists of three core proteins: eIF4E, eIF4G, and eIF4A1. In this study, we focus on repositioning compounds as novel inhibitors of eIF4A1-mediated translation. In order to accomplish this goal, a modified synthetic reporter assay was established. More specifically, a (CGG) $)_{4}$ motif, which confers eIF4A dependency, was incorporated into the 5 -leader region of a luciferase-tdTomato lentiviral reporter construct. The Prestwick Chemical Library was then screened in multiple TNBC cell lines by measuring the tdTomato fluorescent intensity. We identified several cardiac glycosides as potential inhibitors of eIF4A1-mediated translation. Based on our studies, we find that cardiac glycosides inhibit the expression of eIF4A1. To identify a potential mechanism by which this was occurring, we utilized the Integrative Library of Integrated Network-Based Cellular Signatures (iLINCS). Our pursuits led us to the discovery that cardiac glycosides also decrease levels of c-MYC. Quantitative PCR confirmed that decreases in c-MYC and eIF4A were occurring at the transcriptional level. As such, disruption of the eIF4A1-c-MYC axis may be a viable approach in the treatment of TNBC. The novel combination of rocaglamide A and digoxin exhibited synergistic anti-cancer activity against TNBC cells in vitro. The findings in this study and others are important for formulating potential combination chemotherapies against eIF4A1 in vivo. Thus, drug repositioning may be one classical approach to successfully target eIF4A1 in TNBC patients.
\end{abstract}

Keywords: eIF4A1; c-MYC; digoxin; bufalin; rocaglamide A; TNBC; repurposing; repositioning

\section{Introduction}

Triple-negative breast cancer (TNBC) is a subtype of breast cancer that lacks detectable expression of estrogen receptor (ER), human epidermal growth factor receptor 2 (HER2), and progesterone receptor (PR). TNBCs have an increased likelihood of recurrence and mortality in the first 3 years of treatment [1,2]. This is most likely due to the propensity of TNBC to metastasize and lack of effective targeted therapies [3]. Standard neoadjuvant chemotherapy using taxane and anthracycline-based agents is currently the standard-of-care [4,5]. Several promising therapies have emerged in the field including therapeutic antibodies targeting programmed cell death protein 1 (PD-1), and its ligand PD-L1, along with poly ADP ribose polymerase (PARP) inhibitors, but these therapies unfortunately 
only benefit a fraction of patients [6,7]. One of the emerging targets in TNBC is the eukaryotic initiation factor (eIF) $4 \mathrm{~F}$ complex.

The eukaryotic initiation factor (eIF) $4 \mathrm{~F}$ complex regulates the rate-limiting step of translational initiation. This complex consists of the cap binding protein eIF4E, the large scaffolding protein eIF4G, and the DEAD-box RNA helicase eIF4A1. eIF4F assists in the recruitment of the 43S preinitiation complex (PIC) to the messenger RNA [8]. The necessity for the eIF4F complex is largely dependent on the structural diversity of the $5^{\prime}$-leader region [9]. Sequences that contain a high degree of secondary structures (or stem-loops) require the ATP-dependent helicase activity of eIF4A1 to unwind any folding which then allows for the successful recruitment of the PIC to the mRNA.

There has been considerable interest in the eIF4F complex and its vital connection to cancer biology. Several signaling pathways are frequently dysregulated in cancer and these feed into the mTOR complex which ultimately promotes the assembly of eIF4F through a series of phosphorylation reactions [10]. Moreover, eIF4F cancer dependency is largely due to several oncogenic mRNAs containing complex secondary structures in their 5'-leader region. Examples of eIF4F-dependent mRNAs include baculoviral IAP repeat containing 5 (BIRC5), Rho associated coiled-coil containing protein kinase 1 (ROCK1), cyclin D3 (CCND3), c-MYC, and B-cell lymphoma-2 (BCL-2) [11].

The role of eIF4F complex in primary breast tumor progression and metastasis has been studied. Knockdown of eIF4E reduced the migration and invasion of TNBC cells in vitro. Moreover, the loss of eIF4E reduced primary tumor growth and the onset of pulmonary metastasis [12]. Importantly, eIF4A1 and eIF4E were found to be independent predictors of poor outcome in ER-negative breast cancer [13]. Recently, we indicated a role for eIF4A1 in facilitating paclitaxel resistance in TNBC cell lines [14].

As the eIF4F complex immensely supports the cancer proteome to enable primary tumor progression and metastasis, there have been several pursuits to identify inhibitors that disrupt its activity. Some examples include 4E-GI-1 which prevents the protein-protein interaction between eIF4E and eIF4G [15]. In addition, there are several small molecule inhibitors (SMIs) which disrupt the activity of the eIF4A1. This includes pateamine A and hippuristanol $[16,17]$. Among the SMIs of eIF4A1 to date, the best characterized set of inhibitors is the rocaglates. Rocaglates clamp eIF4A1 onto RNA polypurine sequences in an ATP-independent manner. This prevents the participation of eIF4A1 in the eIF4F complex which disrupts 43S PIC recruitment and the translation of the oncogenic mRNAs $[18,19]$. These anti-eIF4A1 inhibitors demonstrated remarkable efficacy in the treatment of TNBC. For example, silvestrol significantly inhibited the growth of MDA-MB-231 orthotopic xenograft tumors [20]. Inhibition of eIF4A is also a promising strategy for other cancer types including pancreatic cancer [21]. New amidino-rocaglate derivatives have recently been developed with an $\mathrm{IC}_{50}$ value as low as $0.97 \mathrm{nM}$ in MDA-MB-231 cells [22,23]. One rocaglate derivative, eFT226 (Zotatifin) has just entered a phase 1 clinical trial in patients with advanced solid tumors (NCT04092673) [24]. Despite the clear and potent anti-cancer activity of eIF4F inhibitors, none are FDA-approved currently.

Drug repositioning or repurposing is the process by which novel uses are found for pre-existing drugs. This approach has several distinct advantages over the conventional drug development pipeline. For example, the biosafety, pharmacokinetic, and pharmacodynamic profiles of any FDA-approved drug are already known which is beneficial in the clinical trial process. One successful example of repositioning compounds as an anti-cancer agent is the use of thalidomide in the treatment of multiple myeloma [25]. Several studies have suggested that commonly used medications such as $\beta$-blockers, angiotensin-converting enzyme (ACE) inhibitors, or statins may actually reduce breast cancer mortality [26].

In this study, we modified an eIF4A1-reporter system to screen the Prestwick Chemical Library consisting of mostly FDA-approved drugs. To our knowledge, this is the first attempt to repurpose compounds as potential inhibitors of eIF4A-mediated translation. Such compounds could potentially show potent anti-cancer activity while making a quick clinical impact. In our drug screening, we identified that cardiac glycosides have the ability to inhibit eIF4A1 through a c-MYC-dependent mechanism. 


\section{Results}

\subsection{Establishment of the (CGG) ${ }_{4}$ Luc2-TdTomato Reporter System}

The (CGG) $)_{4}$ motif located in the $5^{\prime}$-leader region of mRNAs has been recognized to confer eIF4A1 dependency [27]. Early studies characterizing the structural characteristics of the (CGG) ${ }_{4}$ motif have hypothesized the formation of a G-quadruplex. However, the actual existence of G-quadruplexes within the cell remains controversial. Recent evidence has suggested that this motif rather confers eIF4A dependency through the formation of classical secondary structures [28,29]. Irrespective of the precise nature of the secondary structure, we first confirmed the dependency of the (CGG) $)_{4}$ motif on the activity of eIF4A by employing a previously established luciferase assay [27]. Human embryonic kidney-293 (HEK-293) cells were transiently transfected with CMV-luciferase, CMV-(CGG) 4 luciferase, or CMV-random (CGG) 4 luciferase (matched for G/C content) and incubated with silvestrol. There was a significant reduction in the relative luciferase activity for the construct harboring the (CGG) $)_{4}$ motif in the $5^{\prime}$-leader region (Figure 1A). Based on these findings, we created an eIF4A1 reporter gene which harbored a $(\mathrm{CGG})_{4}$ motif immediately upstream of the open reading frame of the luciferase-tdTomato fusion protein (Figure 1B). In order to track the eIF4A1 activity, we can either employ luciferase or tdTomato as the reporter depending on the contextual requirement. Following stable selection with puromycin in multiple TNBC cell lines, successful incorporation and expression of the fusion protein was confirmed by live-cell fluorescent microscopy (Figure 1C). To confirm dependency of the reporter protein on the activity of eIF4A1, the concentration-dependent response of two known eIF4A inhibitors, rocaglamide A and silvestrol, was tested. Rocaglamide A and silvestrol potently reduced Luc2-tdTomato expression levels in a concentration-dependent manner (Figure 1D,E). To further confirm the specificity of our system to eIF4A1, we tested the inhibitory response following the incubation with two cytostatic drugs that are not known to inhibit the helicase activity of eIF4A1, mitoxantrone, and paclitaxel. Both compounds reduced Luc2-tdTomato expression by only $20 \%$ in the same concentration range (Figure $1 F, G$ ). In all, our results suggest that the establishment of a reporter system which does indeed confer eIF4A dependency.

\subsection{Prestwick Chemical Library Screen}

We screened the Prestwick chemical library in order to reposition compounds that potentially inhibit eIF4A1-mediated mRNA translation in TNBC cells. This library contains mostly FDA-approved drugs with known bioavailability and toxicity profiles. To further confirm accuracy of each hit, we decided to screen the library in differing TNBC reporter cell lines. Z-scores, or the number of standard deviations away from the mean fluorescence, was determined for each compound (Figure 2A). When comparing the results between cell lines, cardiac glycosides significantly inhibited Luc2-tdTomato expression in our eIF4A1 reporter system. The individual Z-scores of each compound are listed (Figure 2B). Cardiac glycosides are a class of compounds which are known to inhibit the $\mathrm{Na}^{+} / \mathrm{K}^{+}$-ATPase. These compounds have been used clinically for decades to treat heart failure and atrial arrhythmia [30]. Based on these findings, we further pursued the cardiac glycoside digoxin and its derivative bufalin in our studies. The anti-cancer activity of digoxin has been identified previously [31]. Moreover, bufalin has been shown to inhibit the growth of tumors in a xenograft model of breast cancer [32]. Bufalin has also been reported to inhibit the PI3K-Akt-mTOR pathway which is known to contribute to eIF4F assembly [33]. 


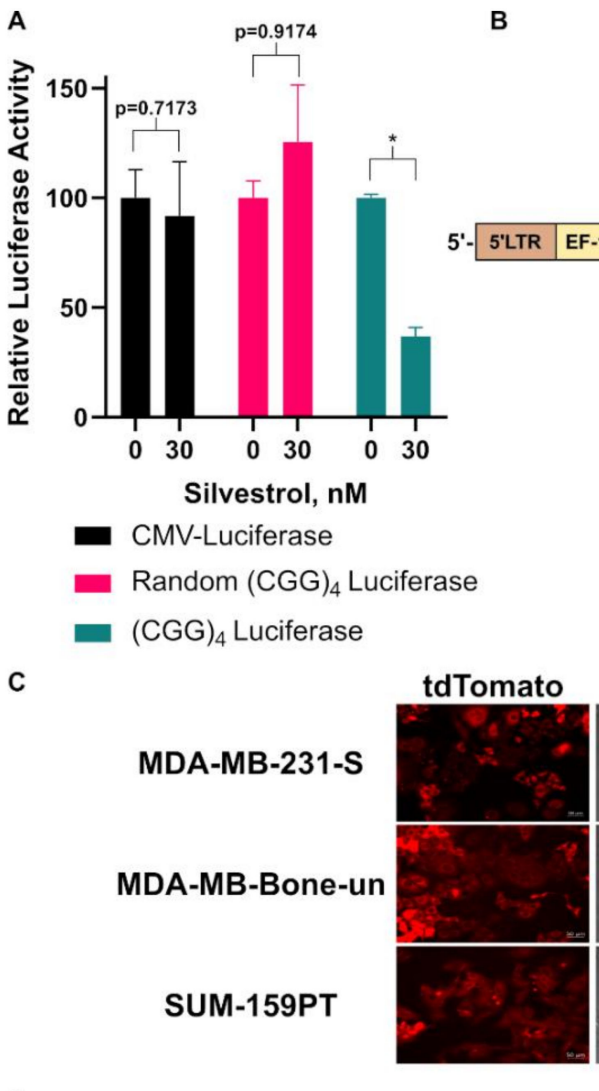

D

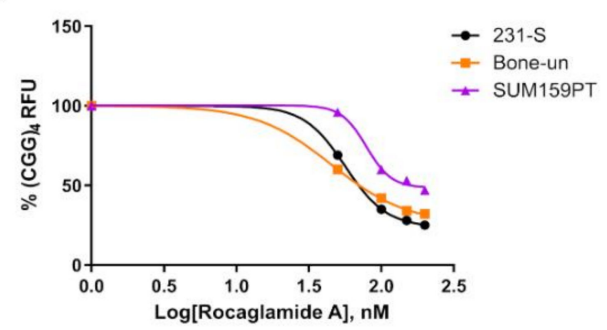

F

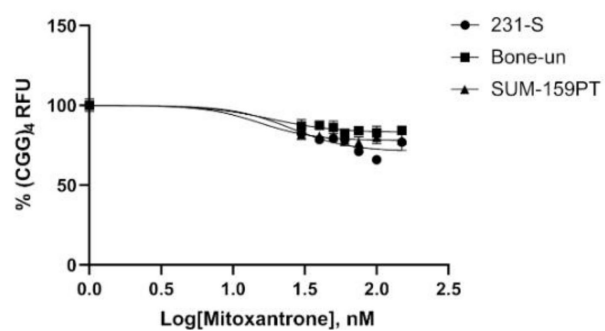

E

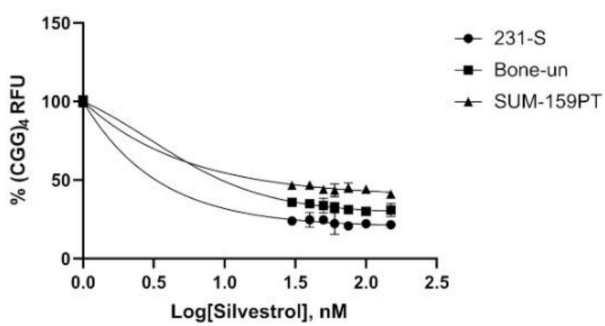

G

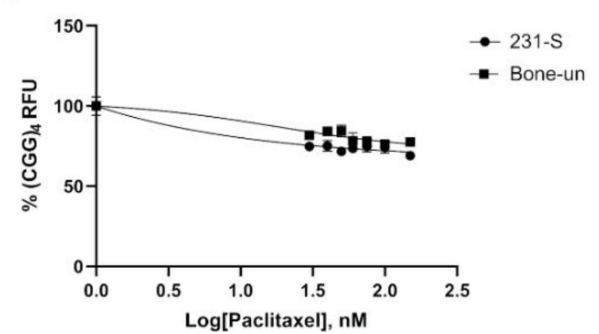

Figure 1. Characterization of the (CGG) ${ }_{4}$ Luc2-tdTomato Reporter System. (A). (CGG) 4 luciferase assay in 293 cells following treatment with $30 \mathrm{nM}$ silvestrol $(n=3)$. Relative luciferase activity indicates the luminescent ratio of luciferase/renilla with untreated cells set to $100 \%$ (* indicates $p<0.05$ as analyzed by a student's t-test). (B). Cartoon representation of the (CGG) $)_{4}$ Luc2-tdTomato reporter plasmid. (C). Live-cell fluorescent images of MDA-MB-231-S, MDA-MB-Bone-un, and SUM-159PT cells after introduction of the (CGG) $)_{4}$ Luc2-tdTomato fusion protein $(n=1)$. (D). (CGG) $)_{4}$ Luc2-tdTomato readings in MDA-MD-231-S, MDA-MB-Bone-un, and SUM-159PT cells following treatment with 0-200 nM rocaglamide A $(n=3)$. (E). (CGG) ${ }_{4}$ Luc2-tdTomato readings in MDA-MD-231-S, MDA-MB-Bone-un, and SUM-159PT cells following treatment with $0-150 \mathrm{nM}$ silvestrol $(n=3)$. (F). (CGG) 4 Luc2-tdTomato readings in MDA-MD-231-S, MDA-MB-Bone-un, and SUM-159PT cells following treatment with 0-150 nM mitoxantrone $(n=3)$. (G). (CGG) $)_{4}$ Luc2-tdTomato readings in MDA-MD-231-S and MDA-MB-Bone-un cells following treatment with $0-150 \mathrm{nM}$ paclitaxel $(n=3)$. 
A
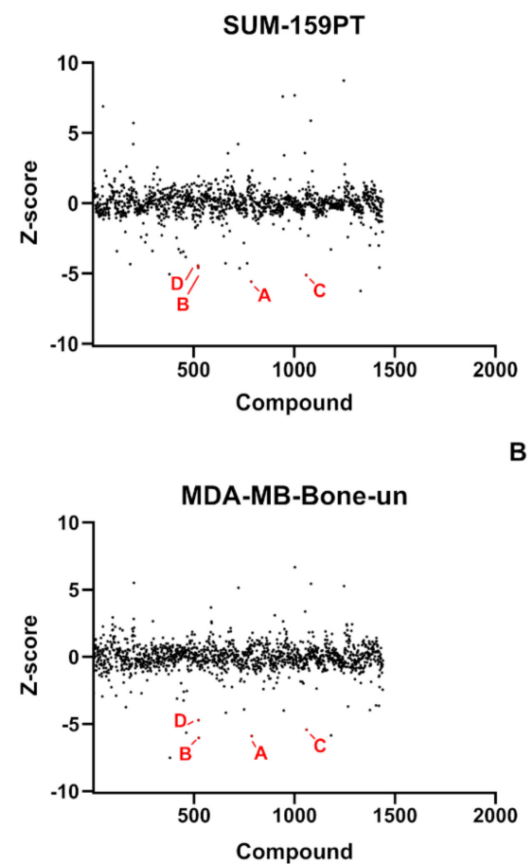

MDA-MB-231-S
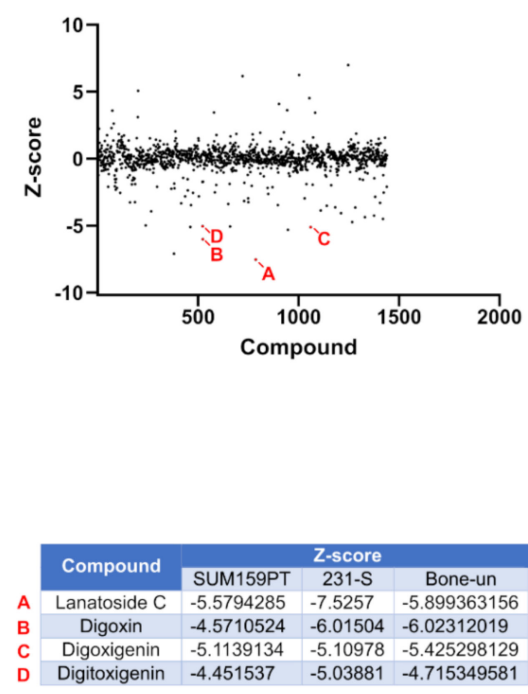

Figure 2. Prestwick Chemical Library Screen. (A). Z-scores for each compound from the Prestwick Chemical Library were calculated for their ability to reduce expression levels of (CGG) 4 Luc2-tdTomato in MDA-MB-231-S, MDA-MB-Bone-un, and SUM-159PT cells $(n=1)$. (B). Individual Z-scores of lanatoside $\mathrm{C}$, digoxin, digoxigenin, and digitoxigenin from each cell line.

\subsection{Cardiac Glycosides Inhibit eIF4A-Mediated Translation in Triple-Negative Breast Cancer Cells}

We further refined the results of our Prestwick screen by investigating the concentration-dependent reduction of (CGG) $)_{4}$-Luc2-tdTomato expression in the three TNBC cell lines (Figure 3A). All three cell lines showed favorable (CGG) ${ }_{4}$ RFU IC $_{50}$ values ranging from $40-90 \mathrm{nM}$ for digoxin (Figure 3B). Previous studies with digoxin have suggested that this compound can significantly inhibit global protein synthesis as inhibition of the $\mathrm{Na}^{+}, \mathrm{K}^{+}$-ATPase depletes cellular potassium which is required for translational elongation [34]. Based on the results of this study, we re-examined our findings from the $(\mathrm{CGG})_{4}$ reporter assay.

To address the toxicity concerns associated with digoxin, we repeated the experiment with 231-S cells, but also normalized the fluorescent readings to total protein values of each well. With total protein normalization, both rocaglamide A and digoxin showed similar (CGG) $\mathrm{RFU} \mathrm{IC}_{50}$ values (Figure $3 \mathrm{C}$ ). Next, we looked at the relative luciferase activity of CMV-luciferase in HEK-293 cells as a generic indicator of total protein synthesis. Concentrations up to $50 \mathrm{nM}$ of digoxin did not have a significant impact on the luciferase activity levels. However, concentrations exceeding $50 \mathrm{nM}$ of digoxin did significantly reduce firefly luciferase activity levels (Figure 3D). These results would support previous reports that digoxin does indeed affect global protein synthesis at high concentrations. However, based on our (CGG) ${ }_{4} \mathrm{IC}_{50}$ values, we believe that a therapeutic window does exist to target eIF4A1 without significant reductions in global protein synthesis. To support this claim, we first confirmed the dependency of two eIF4A targets (BIRC5 and ROCK1) in SUM-159PT cells by treating the cells with rocaglamide A. Levels of BIRC5 and ROCK1 decreased after $48 \mathrm{~h}$ of RocA treatment (Figure 3E). We then treated SUM-159PT cells with 30-50 nM digoxin and observed ROCK1 and BIRC5 decrease in the same time duration of drug treatment, but not $\beta$-tubulin (Figure 3F). Finally, to investigate a potential mechanism by which cardiac glycosides inhibit eIF4A1-mediated translation, we examined the expression levels of all three eIF4F components. Rocaglamide A is known to inhibit eIF4A1 by inducing non-specific binding and clamping to polypurine RNA [18]. We therefore did not expect any reductions in eIF4A1 levels upon rocaglamide A treatment. Interestingly, both digoxin and bufalin significantly reduced protein levels of eIF4A1. Expression levels of eIF4G, but not eIF4E, were also 
reduced by digoxin or bufalin (Figure 3G). We next investigated if reductions in eIF4A protein levels were occurring at the transcriptional level. Digoxin treatment of SUM-159PT cells significantly reduced eIF4A1 mRNA levels along with c-MYC (Figure 3H).

A
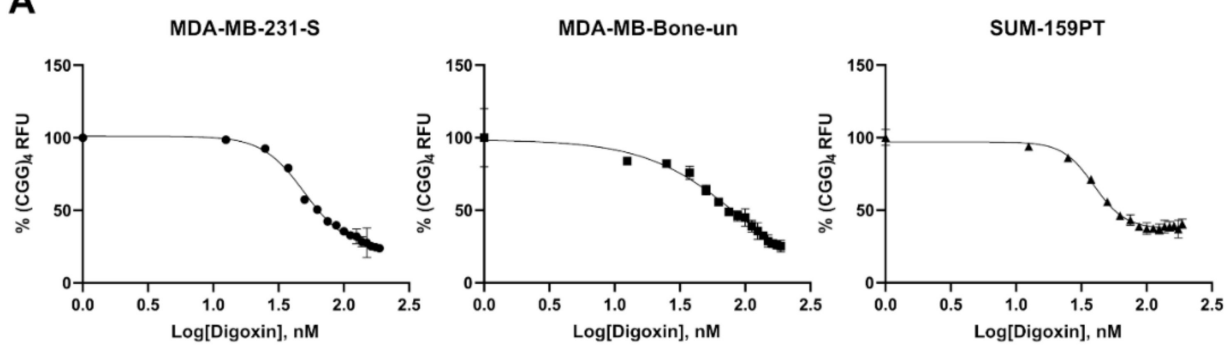

B

C

D
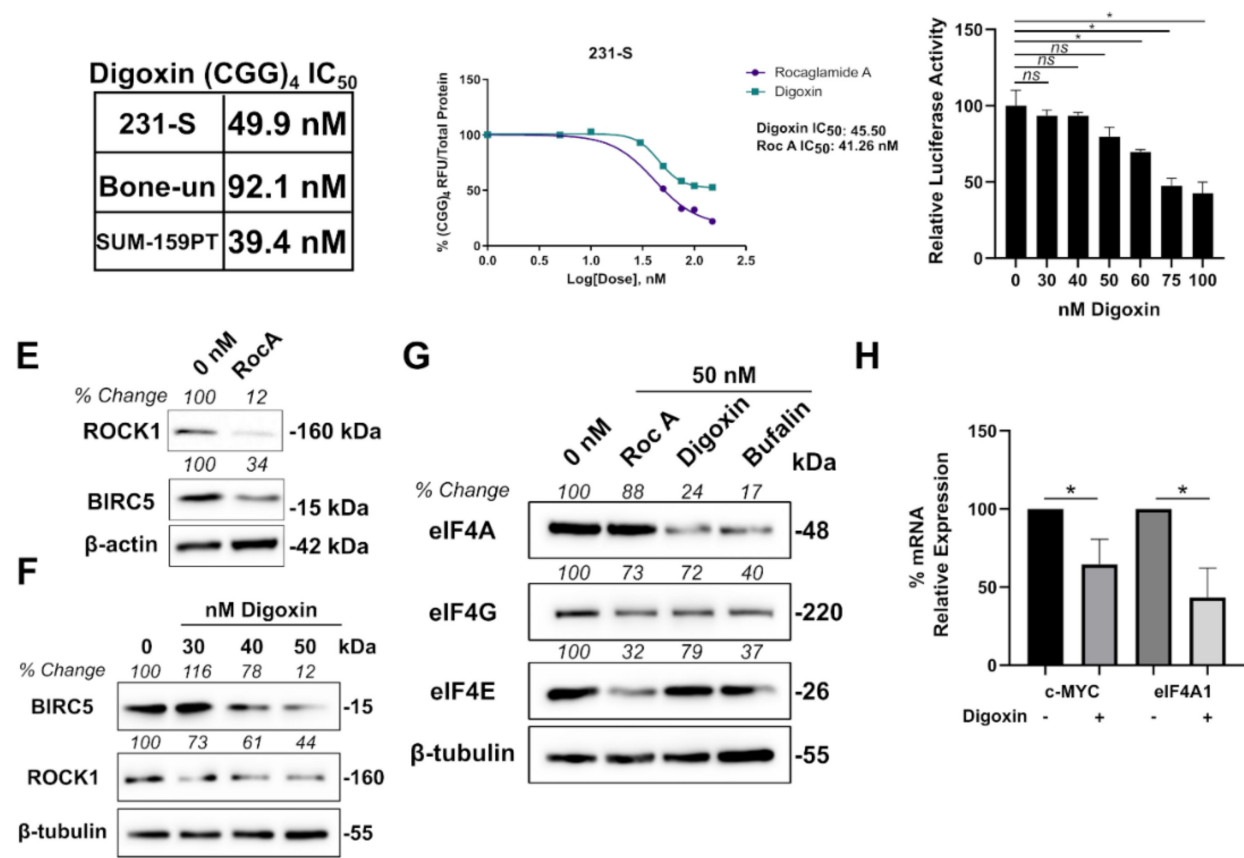

H

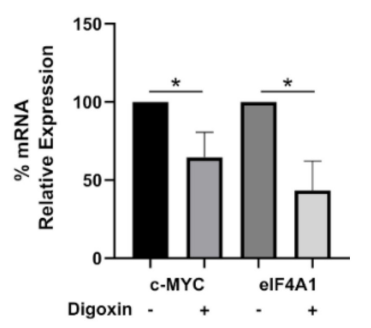

Figure 3. Cardiac glycosides inhibit eukaryotic translation initiation factor 4A complex (eIF4A)-dependent translation in triple-negative breast cancer (TNBC) cells. (A). (CGG) 4 Luc2-tdTomato readings in MDA-MD-231-S, MDA-MB-Bone-un, and SUM-159PT cells following treatment with 0-187.5 $\mathrm{nM}$ digoxin (12.5 nM increments). (B). Calculated (CGG) $\mathrm{IC}_{50}$ values for each cell line. (C). (CGG) Luc2-tdTomato/total protein readings (A595) in MDA-MD-231-S cells following treatment with either 0-150 nM digoxin or rocaglamide A. (D). CMV-Luciferase/RTK Renilla expression readings in 293 cells following treatment with $0-100 \mathrm{nM}$ digoxin $\left({ }^{*}\right.$ indicates $p<0.05$ as analyzed by a one-way ANOVA with a Bonferroni post hoc test). (E). Western blots following treatment with $50 \mathrm{nM}$ rocaglamide A for $48 \mathrm{~h}$ in SUM-159PT cells. Band intensities were calculated by densitometry based on the ratio of each target gene (BIRC5 or ROCK1) normalized to the $\beta$-actin protein signal with $0 \mathrm{nM}$ set to 100 . (F). Western blots following treatment with $0-50 \mathrm{nM}$ digoxin for $48 \mathrm{~h}$ in SUM-159PT cells. Band intensities were calculated based on the ratio of each target gene (BIRC5 or ROCK1) normalized to the $\beta$-tubulin protein signal with $0 \mathrm{nM}$ set to 100. (G). Western blots following treatment with $50 \mathrm{nM}$ of each indicated drug for $72 \mathrm{~h}$ in SUM-159PT cells. Band intensities were calculated based on the ratio of each target gene (eIF4A, eIF4G, or eIF4E) normalized to the $\beta$-tubulin protein signal with $0 \mathrm{nM}$ set to 100 . Uncropped Blots are shown in Figure S2. (H). Quantitation of mRNA levels by qPCR from SUM-159PT cells following the treatment of $50 \mathrm{nM}$ digoxin. Data were analyzed using the $\Delta \Delta \mathrm{Ct}$ method with $\beta$-tubulin as the control. Relative expression was calculated with DMSO-treated cells set to $100 \%$ (* indicates $p<0.05$ as analyzed by a one-way ANOVA with a Bonferroni post hoc test). 


\subsection{Cardiac Glycosides Modulate eIF4A1 Expression Levels through c-MYC}

We next wanted to further elucidate the mechanism by which cardiac glycosides were decreasing the protein levels of eIF4A1. The Library of Integrated Network-Based Cellular Signatures (LINCS) is a National Institute of Health (NIH) sponsored program which catalogs proteomic and transcriptomic perturbation-response signatures across several cancer types. Integrated LINCS (iLINCS) is a biologist friendly extension of this program which allows for easy identification and analysis of these signatures. When examining biological processes affected by digoxin or bufalin in other systems, transcription was largely impacted $[35,36]$. Both digoxin and bufalin-treated MCF7 gene set enrichment analyses suggested that c-MYC was largely affected (Tables 1 and 2). This data affirms previous reports that cardiac glycosides are known inhibitors of c-MYC [37,38]. To further validate this claim, we treated BT20 cells (another TNBC cell line) with only $30 \mathrm{nM}$ of digoxin or bufalin and observed a time-dependent decrease in the levels of c-MYC (Figure 4A).

The c-MYC-eIF4F axis has been established to be an important mediator of tumorigenesis $[39,40]$. Moreover, the eIF4F complex and c-MYC are in a positive feedback loop with one another. Expression levels of c-MYC are regulated by the presence of secondary structure in its $5^{\prime}$-leader region. Components of the eIF4F complex are then in turn transcriptionally regulated by c-MYC [41]. Based on this literature and our own findings, we hypothesized that cardiac glycosides could inhibit eIF4A1-mediated translation through modulations in c-MYC levels. To test this hypothesis, we first examined at the number of MYC binding sites in the promoters of eIF4A1, eIF4E, and eIF4G. All three promoters contained putative MYC binding sites with eIF4A1 containing only one (Table 3). Next, we confirmed decreases in c-MYC and eIF4A levels in SUM-159PT cells upon treatment with digoxin. Cyclin D3 and BIRC5 levels also decreased in a time-dependent fashion suggesting that eIF4A1 was indeed affected. Moreover, the levels of eIF4G, but not eIF4E also decreased (Figure 4B). Next, we tested a c-MYC/Max dimerization inhibitor that has shown anti-cancer activity in breast cancer xenografts [42]. Kj Pyr 9 did show a concentration-dependent (CGG) 4 RFU reduction in 293-HA-CXCR4 cells, although the $\mathrm{IC}_{50}$ value $(9.7 \mu \mathrm{M})$ was quite high (Figure S1). This could be attributed to "undruggable" nature of c-MYC, a problem that the field has faced for decades [43]. Lastly, to support the specificity of our proposed hypothesis, we employed the 'forced overexpression' of eIF4A1 or c-MYC in 293-HA-CXCR4 cells with bufalin treatment. Overexpression of either eIF4A or c-MYC significantly reduced the reduction of (CGG) ${ }_{4}$ Luc2-tdTomato by bufalin at high concentrations (Figure S1).

A

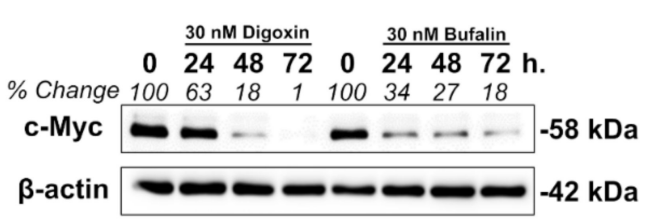

B

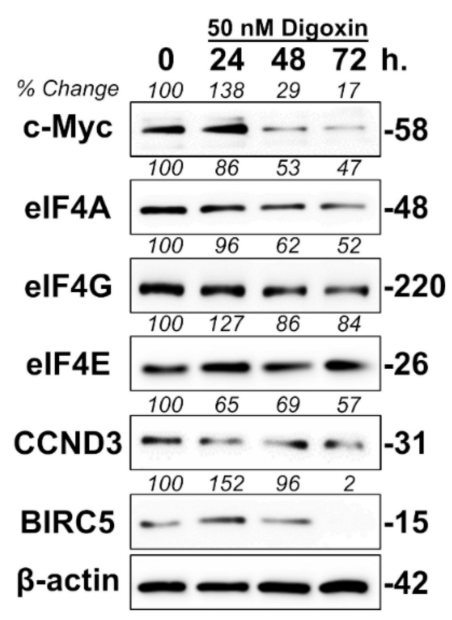

Figure 4. Cardiac glycosides modulate eIF4A expression levels through c-MYC (A). Western blot of BT20 cells following treatment with $30 \mathrm{nM}$ of digoxin or bufalin for the indicated times. Band intensities were calculated by densitometry based on the ratio of c-MYC normalized to $\beta$-actin with $0 \mathrm{~h}$ set to 100 for each compound. (B). Western blot of SUM-159PT cells following treatment with $50 \mathrm{nM}$ digoxin for the indicated times. Band intensities were calculated based on the ratio of each target normalized to $\beta$-actin with $0 \mathrm{~h}$ set to 100 . Uncropped blots are shown in Figure S2 
Table 1. Digoxin gene set enrichment analysis.

\begin{tabular}{cccccccc}
\hline Term & Overlap & $p$-Value & $\begin{array}{c}\text { Adjusted } \\
p \text {-Value }\end{array}$ & $\begin{array}{c}\text { Old } \\
p \text {-Value }\end{array}$ & $\begin{array}{c}\text { Old } \\
\text { Adjusted } \\
p \text {-Value }\end{array}$ & $\begin{array}{c}\text { Odds } \\
\text { Ratio }\end{array}$ & $\begin{array}{c}\text { Combined } \\
\text { Score }\end{array}$ \\
\hline $\begin{array}{c}\text { MYC oe MCF7 human } \\
\text { gse101738 RNAseq down }\end{array}$ & $11 / 159$ & $\begin{array}{c}4.36 \times \\
10^{-10}\end{array}$ & $8.54 \times 10^{-7}$ & 0 & 0 & 13.83647799 & 298.2241 \\
$\begin{array}{c}\text { SREBF2 KD human gse50588 } \\
\text { creedsid gene 2823 up }\end{array}$ & $12 / 294$ & $2.70 \times 10^{-8}$ & $2.64 \times 10^{-5}$ & 0 & 0 & 8.163265306 & 142.2611 \\
$\begin{array}{c}\text { STAT3 KD human gse42979 } \\
\text { creedsid gene 2148 down }\end{array}$ & $12 / 309$ & $4.67 \times 10^{-8}$ & $3.05 \times 10^{-5}$ & 0 & 0 & 7.766990291 & 131.1075 \\
$\begin{array}{c}\text { HEY2 KO mouse gse6526 } \\
\text { creedsid gene 1511 up }\end{array}$ & $9 / 205$ & $8.91 \times 10^{-7}$ & $3.49 \times 10^{-4}$ & 0 & 0 & 8.780487805 & 122.3245 \\
$\begin{array}{c}\text { HEY2 KO mouse gse6526 } \\
\text { creedsid gene 1512 down }\end{array}$ & $9 / 205$ & $8.91 \times 10^{-7}$ & $2.91 \times 10^{-4}$ & 0 & 0 & 8.780487805 & 122.3245 \\
\hline
\end{tabular}

Table 2. Bufalin gene set enrichment analysis.

\begin{tabular}{cccccccc}
\hline Term & Overlap & $p$-Value & $\begin{array}{c}\text { Adjusted } \\
p \text {-Value }\end{array}$ & $\begin{array}{c}\text { Old } \\
p \text {-Value }\end{array}$ & $\begin{array}{c}\text { Old } \\
\text { Adjusted } \\
p \text {-Value }\end{array}$ & $\begin{array}{c}\text { Odds } \\
\text { Ratio }\end{array}$ & $\begin{array}{c}\text { Combined } \\
\text { Score }\end{array}$ \\
\hline $\begin{array}{c}\text { MYC oe MCF7 human } \\
\text { gse101738 RNAseq down }\end{array}$ & $8 / 159$ & $1.34 \times 10^{-6}$ & $8.74 \times 10^{-4}$ & 0 & 0 & 10.0628931 & 136.0840 \\
$\begin{array}{c}\text { ZNF143 siRNA MCF7 human } \\
\text { gse76453 RNAseq down }\end{array}$ & $10 / 233$ & $2.63 \times 10^{-7}$ & $5.15 \times 10^{-4}$ & 0 & 0 & 8.58369099 & 130.0552 \\
$\begin{array}{c}\text { STAT3 deficiency mouse } \\
\text { gse6846 creedsid gene 85 down } \\
\text { FOXO1 KD mouse gse6623 } \\
\text { creedsid gene 505 down }\end{array}$ & $10 / 246$ & $4.33 \times 10^{-7}$ & $4.24 \times 10^{-4}$ & 0 & 0 & 8.1300813 & 119.1174 \\
$\begin{array}{c}\text { SREBF2 KD human gse50588 } \\
\text { creedsid gene 2823 up }\end{array}$ & $10 / 294$ & $6.12 \times 10^{-6}$ & 0.001711 & 0 & 0 & 8.20512821 & 98.4977 \\
\hline
\end{tabular}

Table 3. c-MYC putative promoter binding analysis.

\begin{tabular}{cccccccc}
\hline Gene & $\begin{array}{c}\text { Factor } \\
\text { Name }\end{array}$ & $\begin{array}{c}\text { Start } \\
\text { Position }\end{array}$ & $\begin{array}{c}\text { End } \\
\text { Position }\end{array}$ & Dissimilarity & String & $\begin{array}{c}\text { Random } \\
\text { Expectation } \\
\text { Equally }\end{array}$ & $\begin{array}{c}\text { Random } \\
\text { Expectation } \\
\text { Query }\end{array}$ \\
\hline eIF4A & $\begin{array}{c}\text { c-MYC } \\
\text { (T00140) }\end{array}$ & & & & & & \\
eIF4E & 204 & 209 & 0.000000 & CACGTG & 0.14648 & 0.19526 \\
& & 266 & 271 & 0.000000 & CACGTG & 0.14648 & 0.16595 \\
eIF4G & 419 & 424 & 0.000000 & CACGTG & 0.14648 & 0.16595 \\
& & & & & & & \\
& & 355 & 360 & 0.000000 & CACGTG & 0.14648 & 0.18917 \\
& & 432 & 437 & 0.000000 & CACGTG & 0.14648 & 0.18917 \\
\hline
\end{tabular}

2.5. The Combination of Cardiac Glycosides and Rocaglates are Synergistic in Inhibiting TNBC Cells in Vitro

Retrospective studies examining digoxin use in cancer patients has showed no survival advantages in recent years. However, digoxin usage does not increase mortality suggesting that it is safe to use in breast cancer patients at currently prescribed doses [44]. In addition, the toxicity of these compounds, especially against breast epithelial cells, has been raised by other groups [45]. Based on these findings, digoxin could be a good candidate for a combinatorial therapy in this population group especially at low-moderate doses. Due to the observation that digoxin could reduce total levels of eIF4A1, we hypothesized that cardiac glycosides could be synergistic with a known eIF4A1 inhibitor such as rocaglamide A. Cell viability experiments in SUM-159PT cells showed a synergistic effect with the combination of rocaglamide A and digoxin from 0-150 nM (Figure 5A). Moreover, to confirm that this phenomenon was not cell-type or digoxin-specific, we also tested the combination of rocaglamide A and bufalin in BT-549 cells from 0-70 nM (Figure 5B). The eIF4F complex regulates the mRNA 
translation of several anti-apoptotic proteins (like BCL-2 and myeloid cell leukemia 1 (MCL-1)) and rescues cells from caspase-mediated apoptosis [46]. We therefore visualized cleaved caspase 3/7 in live SUM-159PT cells. The combination of rocaglamide A and digoxin resulted in more caspase 3/7 cleavage over that of rocaglamide A alone (Figure 5C). To confirm our caspase 3/7 staining data, we also probed for an additional apoptotic marker. The combination of digoxin and rocaglamide A resulted in the largest increase of cleaved PARP following drug treatment (Figure 5D). In all, our results suggest that targeting of the c-MYC-eIF4A axis could be a beneficial and synergistic combination for TNBC patients (Figure 6).

A

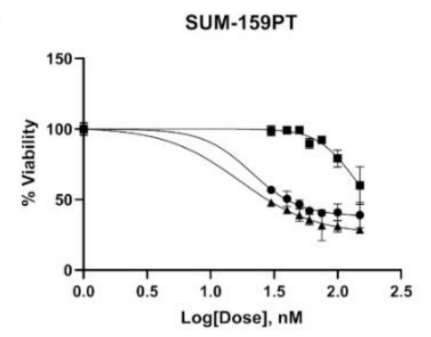

- Rocaglamide A

- Digoxin

$\star$ Combination

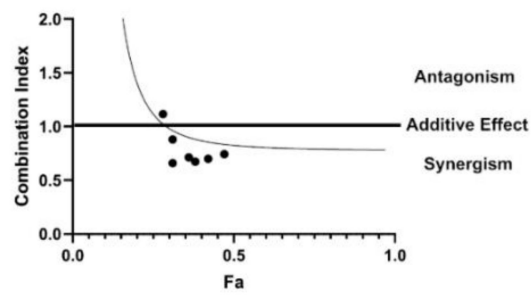

B

BT-549
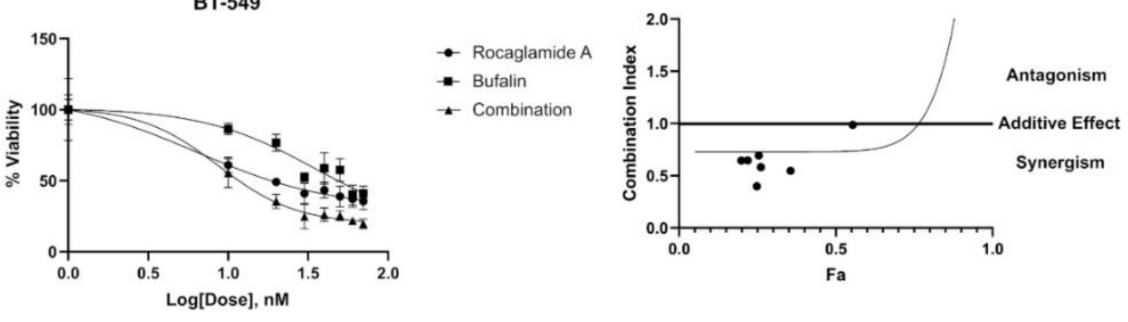

C
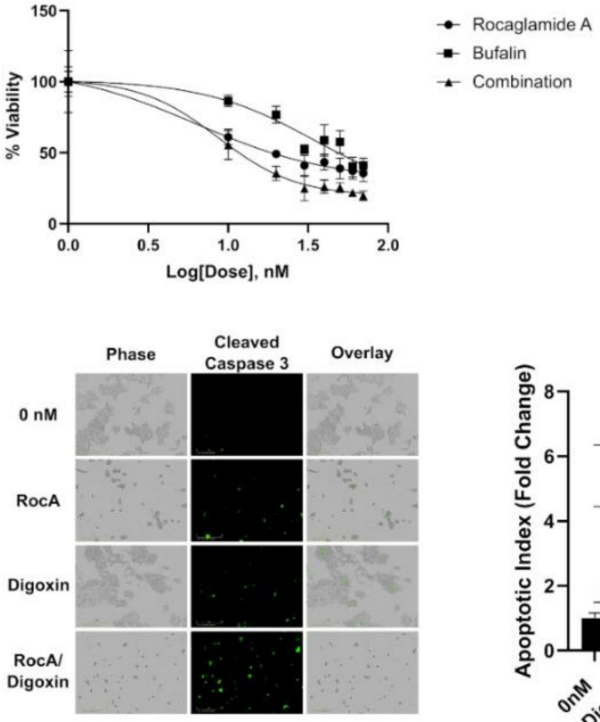

D

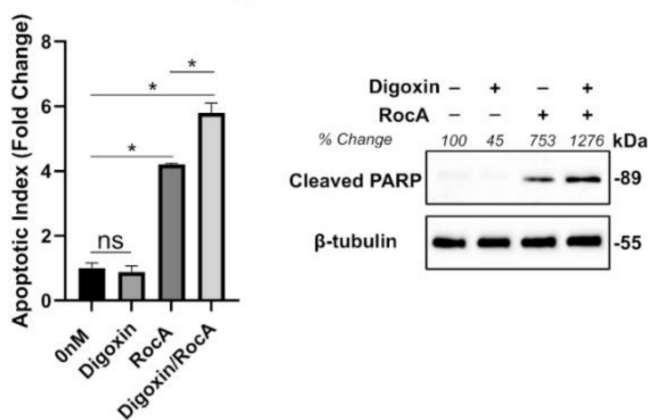

Figure 5. Rocaglates in combination with cardiac glycosides are synergistic in inhibiting TNBC cells in vitro. (A). Cell viability readings using Cell Titer GLO in SUM-159PT cells following the treatment of rocaglamide A, digoxin, or the combination of both (0-150 nM). (B). Cell viability readings using Cell Titer Blue in BT-549 cells following the treatment of rocaglamide A, bufalin, or the combination of both $(0-70 \mathrm{nM})$. (C). Cleaved caspase 3 staining in SUM-159PT cells following treatment with rocaglamide A, digoxin, or the combination of both $(50 \mathrm{nM})$ after $24 \mathrm{~h}$. Apoptotic index was calculated based on the total green object integrated intensity normalized to the \% confluence of each image $\left({ }^{*}\right.$ indicates $p<0.05$ as analyzed by a one-way ANOVA with Bonferroni post hoc test). (D). Western blots following treatment with $50 \mathrm{nM}$ of digoxin, rocaglamide A, or the combination of both for $48 \mathrm{~h}$ in SUM-159PT cells. Band intensities were calculated by densitometry based on the ratio of cleaved poly ADP ribose polymerase (PARP) normalized to the $\beta$-tubulin protein signal with $0 \mathrm{nM}$ set to 100 . Uncropped blots are shown in Figure S2. 


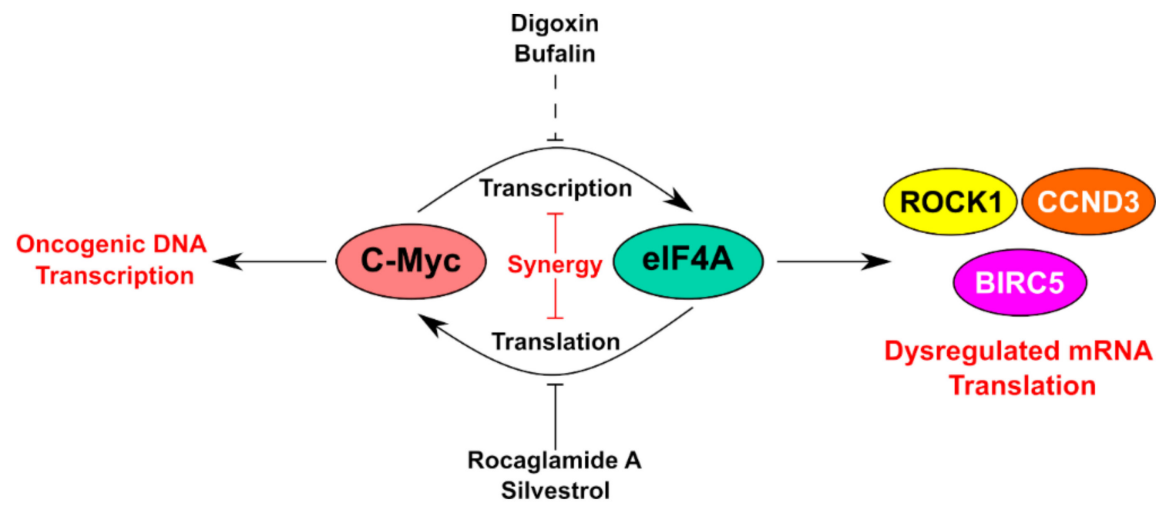

Figure 6. Proposed combinatorial targeting of eIF4A in TNBC cells. Inhibition of eIF4A, both directly and through modulation of upstream regulators (c-Myc), may prove synergistic as an anti-cancer therapy for triple-negative breast cancer patients.

\section{Discussion}

In this study, we identified several cardiac glycosides such as lanatoside $\mathrm{C}$, digoxin, digoxigenin, and digitoxigenin to reduce the activity of eIF4A1. We continued the study with digoxin as its anti-cancer properties are under current clinical investigation (NCT03928210). We also employed bufalin to indicate that our findings were not digoxin specific. In our study, we found that digoxin and other cardiac glycosides are capable of reducing the total protein levels of eIF4A1. This was reflected in the loss of viability of several TNBC cell lines. Based on our data and dosing range, we did not observe a significant induction of apoptosis with digoxin treatment alone. However, when digoxin was combined with RocA, the level of induction of cleaved caspase- 3 was further enhanced. This was confirmed with cleaved PARP, a second apoptotic marker.

Interestingly, digoxin has also been suggested to affect other biological processes such as anoikis and cellular signaling. In a screen of over 2000 off-patent drugs and natural products, digoxin was identified to induce cell death in anoikis-resistant suspension cultures of prostate adenocarcinoma cells [47]. Digoxin also appears to affect prominent oncogenic signaling nodes such as the cytosolic tyrosine kinase c-Src [48,49]. Recently, there has been renewed interest in digoxin for its ability to target senescent tumor cells. Cardiac glycosides were also identified to induce senolytic activity in cancer cells. The combination of senogenic (doxorubicin) and senolytic (digoxin) compounds showed remarkable synergy in inhibiting a patient-derived xenograft model of breast cancer [50]. Digoxin monotherapy was demonstrated to reduce the lymphatic dissemination in a xenograft model of breast cancer [51].

Here, we demonstrate that there was an observed decrease in both the mRNA and protein levels of eIF4A1 following digoxin treatment. This could be due to the observed decrease in the levels of the transcription factor c-MYC. MYC is known to transcriptionally regulate the protein level of eIF4A1 [41]. In support of our observations, an innovative high-throughput screen of various compounds identified cardiac glycosides as potent inhibitors of c-MYC expression. This was determined with a CRISPR-Cas9 engineered multiple myeloma cell line which had one allele of c-MYC tagged with GFP [38]. Importantly, cardiac glycosides were shown to inhibit the expression of c-MYC at the transcriptional level and we also confirmed this finding. Moreover, the ability of bufalin (a derivative of digoxin) to reduce c-MYC levels was demonstrated in xenograft models of pancreatic cancer [52].

There is a long-standing interest in the role of c-MYC and regulation of translational initiation [53]. For breast epithelium, c-MYC is required in the translational regulation of lactation and alveologenesis [54]. However, cancers are highly dependent on the activity of c-MYC to sustain mRNA translation [55]. More specifically, the eIF4F complex and c-MYC cooperate to promote tumorigenesis. Earlier studies found that c-MYC and eIF4E cooperate and facilitate immortalization of rat primary fibroblasts [56]. In cooperation with eIF4F, which helps to translate a variety of anti-apoptotic proteins, tumorigenesis is greatly accelerated [40]. Targeting of eIF4F in MYC-driven models of cancer greatly reduces tumor initiation [57]. Preventing the release of eIF4E by reducing phosphorylation levels of 
4E-BP1 with mTOR inhibitors has also been another approach [58]. The c-MYC-eIF4E axis has also been extended to cancer immunotherapy. Reductions in p-eIF4E level with a MNK1/2 inhibitor reduced the expression of PD-L1 in a MYC/KRAS model of cancer [59]. Recently, c-MYC has also been shown to control 4E-BP1 levels [60]. This could be one translational control mechanism to reduce MYC-induced cellular stress.

Based on our data and the findings in the literature, we believe that a therapeutic window does exist to target eIF4A1 with cardiac glycosides. This comes from a growing evidence that in addition to inhibiting the $\mathrm{Na}^{+} / \mathrm{K}^{+}$-ATPase, cardiac glycosides also significantly impact the transcriptional regulation of proteins. Bufalin was shown to directly bind and promote the proteasome-mediated degradation of the steroid receptor coactivator (SRC) family of transcription factors [32]. Interestingly, SRC-1 was demonstrated to interact with Ets2 to increase c-MYC mRNA levels [61]. We showed that digoxin or bufalin treatment resulted in significant reductions of expression levels of both eIF4A1 and c-MYC. This is most likely occurring at the transcriptional level. Consistently, of the three eIF4F components, eIF4A1 was the most sensitive to a reduction by these compounds. This could be due to the fact that eIF4A only contains one c-MYC binding site in its promoter whereas eIF4E and eIF4G contain two sites.

Despite numerous studies suggesting that digoxin and other cardiac glycosides are beneficial for the treatment of cancer, epidemiological studies have yielded inconsistent results. This could be due to the narrow therapeutic window of these compounds. In other words, efficacious concentrations cannot be obtained in the tumor without considerable toxicity in the patient. Due to the structural similarity to estrogen, several studies have suggested that digoxin may actually increase the risk for estrogen receptor positive breast cancer $[62,63]$. Based on these findings, we hypothesized that digoxin may be a good candidate at lower doses in combinatorial therapies for TNBC patients. The combination of rocaglamide A and digoxin or bufalin was shown to be synergistic in inhibiting the viability of TNBC cells. Inhibiting expression levels of eIF4A1 would thereby require decreased doses of rocaglamide A. Disruption of the c-MYC-eIF4F positive feedback loop could explain the synergistic effect. These findings could have future implications for Zotatifin (eFT226), a rocaglate currently in phase 1 clinical trials (NCT04092673).

\section{Materials and Methods}

\subsection{Cell Culture}

MDA-MB-231 breast cancer cells were previously sorted for high cell surface expression of CXCR4 (denoted as 231-S) [64]. Human embryonic kidney 293 cells stably expressing human CXCR4 (denoted 293-HA-CXCR4) are also previously described [64]. MDA-MD-Bone-un cells are a bone metastatic variant of MDA-MB-231 cells [65]. Finally, 293-Parental, SUM-159PT, BT-20, and BT-549 cells were used in this study. Cells were maintained in high glucose Dulbecco's Modified Eagle Medium (DMEM) (GE Healthcare Life Sciences, Pittsburgh, PA, USA, Cat. No. SH30243.01), $10 \%$ heat-inactivated fetal bovine serum (Denville Scientific, Swedesboro, NJ, USA, Cat. No. FB5001-H), and $1 \%$ Penicillin/Streptomycin solution (Corning, Corning, NY, USA, Cat. No. 30-002-CI).

\subsection{Plasmids}

Construction of the plasmids used in the (CGG) $)_{4}$ luciferase assay were described previously [66]. To create an eIF4A reporter gene, the (CGG) $)_{4}$ motif was inserted upstream of the Luciferase-dtTomato fusion protein. pCDH-2A-Luc2-dtTomato was a gift from Dr. Shi-He Liu (University of Toledo, Toledo, OH, USA). Previously, Luc2-dtTomato was inserted into the backbone of pCDH-EF1 $\alpha$-MCS-T2A-Puro (Systems Biosciences, Palo Alto, CA, USA, Cat. No. CD527A-1). The (CGG) $)_{4}$ motif was amplified from the CMV GQ 5'UTR luciferase plasmid by using the following primers: $5^{\prime}$-CTAGCTTCTAGACTAGGTTGAAAGTAC- $3^{\prime}$ and $5^{\prime}$-AGCTAGGAATTCTTTACTATTCTAATCCG-3'. The (CGG) ${ }_{4}$ motif was then incorporated into the 
pCDH plasmid using added XbaI (5'end) and EcoRI ( $3^{\prime}$ end) restriction sites. The open reading frame of eIF4A1 was a gift from Dr. Nahum Sonenberg (Mcgill University, Montreal, QC, Canada). To create an overexpression vector, eIF4A1 was amplified using the following primers: $5^{\prime}$-CTAGCTGGATCCACC ATGTCTGCGAGTCAGGATTC-3' and 5'-CTAGCTGCGGCCGC TCAAATGAGGTCAGCAAC-3' . eIF4A1 was inserted into pcDNA3.0 (Invitrogen, Carlsbad, CA, USA, Cat. No. V79020) using added BamHI ( $5^{\prime}$ end) and NotI ( $3^{\prime}$ end) sites. pcDNA3.0-c-MYC was a gift from Dr. Nagalakshmi Nadiminty (University of Toledo, Toledo, OH, USA).

\subsection{Compounds and Drug Treatments}

All compounds were purchased from MedChemExpress (Monmouth Junction, NJ, USA) and dissolved in DMSO. This includes rocaglamide A (Cat. HY-19356), silvestrol (Cat. HY-13251), mitoxantrone (HY-13502), paclitaxel (HY-B0015), digoxin (HY-B1049), and bufalin (HY-N0877). Drug containing media was only added at the beginning of the experiment. " $0 \mathrm{nM}$ " in all experiments signifies the DMSO control. If multiple concentrations were used, the amount of DMSO was matched to the highest drug condition.

\subsection{Luciferase Assays}

A total of $50 \mathrm{ng}$ of each (CMV, CMV random (CGG) $)_{4}$, or CMV (CGG) 4 ) pGL4.10 luciferase (Promega, Madison, WI, USA, Cat. No. E6651) was transfected along with 50 ng of pGL4.74 hRluc (Promega, Madison, WI, USA, Cat. No. E6921) using FuGENE 6 (Promega, Madison, WI, USA, Cat. No. E2691) in 293 cells using the manufacturer's instructions. Firefly and renilla luciferase activity were taken $48 \mathrm{~h}$ later by using the Dual-Luciferase ${ }^{\circledR}$ Reporter Assay System (Promega, Madison, WI, USA, Cat. No. E1910) and a SpectraMax iD5 plate reader.

\subsection{Generation of (CGG) $)_{4}$ Reporter Cell Lines}

The (CGG) 4 -Luc2-tdTomato fusion protein was stably inserted into the genome of MDA-MB-231-S, MDA-MB-Bone-un, SUM-159PT, and 293-HA-CXCR4 by lentiviral transduction. Virus was first packaged into 293-FT cells. T75 flasks were transfected with $4 \mu \mathrm{g}$ of psPAX2, $2 \mu \mathrm{g}$ pMD2.G, and $7 \mu \mathrm{g}$ of pCDH-2A-(CGG) 4 -Luc2-dtTomato using Fugene 6 (Promega, Madison, WI, USA, Cat. E2691) according to the manufacturer's instructions. Lentivirus was collected at the 48- and 72-h time points. Viral samples were concentrated using Amicon ${ }^{\circledR}$ Ultra-15 Centrifugal $10 \mathrm{kDa}$ Filter Units (Millipore Sigma, St. Louis, MO, USA, Cat. UFC901024). Lentivirus was added to cells overnight along with polybrene $(8 \mu \mathrm{g} / \mathrm{mL})$ (Millipore Sigma, St. Louis, MO, USA, Cat. H9268). The next day media was removed, and cells were continually selected in $2 \mu \mathrm{g} / \mathrm{mL}$ of puromycin (Millipore Sigma, St. Louis, MO, USA, Cat. P8833).

\section{6. (CGG) $)_{4}$-Luc2-tdTomato and Total Protein Readings}

Reporter cells were seeded into black/clear bottom 96-well plates and allowed to attach overnight (Corning, Oneonta, NY, USA, Cat. 3603). Full-serum and drug-containing media was then added the next day. Cells were incubated for 48 hours at $37^{\circ} \mathrm{C} / 5 \% \mathrm{CO}_{2}$. Each well was then washed one time with $1 \times$ phosphate-buffered saline, pH 7.5 (PBS) and additional PBS was added for each reading. Fluorescent measurements were taken on a SpectraMax iD5 plate reader (Molecular Devices, San Jose, CA, USA). The $541_{\text {excitation}} / 581_{\text {emission }}$ well-scan readings were taken with 9 data points in each well (pattern: fill/density: 3/point spacing: 1.90). For plates with total protein readings, PBS was replaced with $1 \times$ PBS/0.1\% IGEPAL CA-630 (Millipore Sigma, St. Louis, MO, USA, Cat. 56741) and nutated for 20 min. Protein Bradford reagent (Bio-Rad, Hercules, CA, USA, Cat. 5000006) was added to each well. A595 readings were taken on the SpectraMax iD5 plate reader with standard endpoint settings. 


\subsection{Prestwick Chemical Library Screen}

The Prestwick Chemical Library was a gift from Dr. Kevin Pan (University of Toledo, Toledo, $\mathrm{OH}$, USA). Compounds were tested at a final concentration of $5 \mu \mathrm{M}$ for $48 \mathrm{~h}$ before (CGG) ${ }_{4}$ RFU readings were obtained. The Z-score was calculated for each compound. More specifically, the following equation was used: $\left.\left[(C G G)_{4} \text { RFU Compound X-(CGG }\right)_{4}\right)$ RFU average of each 96 well plate]/(CGG $)_{4}$ RFU standard deviation of the 96-well plate.

\subsection{Western Blotting}

Cell lysates were prepared by lysing the cells in the following buffer: $50 \mathrm{mM}$ Tris $\mathrm{pH}$ 8.0, $100 \mathrm{mM} \mathrm{NaCl}, 0.1 \%$ IGEPAL CA-630, 0.1\% Deoxycholate, $5 \mathrm{mM}$ EDTA, protease inhibitor cocktail (Sigma-Aldrich, St. Louis, MO, USA, Cat. No. P8340-5ML), phosphatase inhibitor cocktail 2 (Sigma-Aldrich, St. Louis, MO, USA, Cat. No. P5726), and phosphatase inhibitor cocktail 3 (Sigma-Aldrich, St. Louis, MO, USA, Cat. No. P0044). Lysates were nutated for 10 min at $4{ }^{\circ} \mathrm{C}$ and centrifuged for $10 \mathrm{~min}$ at 10,000 RPM. Supernatants were quantified using protein bradford reagent and loaded onto an SDS-PAGE gel. Following transfer onto nitrocellulose, membranes were incubated with the following primary antibodies: eIF4A1 (Cell Signaling Technology, Danvers, MA, USA, Cat. 2490), eIF4E (Cell Signaling Technology, Danvers, MA, USA, Cat. 2067), eIF4G (Cell Signaling Technology, Danvers, MA, USA, Cat. 2469), BIRC5 (Cell Signaling Technology, Danvers, MA, USA, Cat. 2808), CCND3 (Cell Signaling Technology, Danvers, MA, USA, Cat. 2936), c-MYC (Proteintech, Rosemont, IL, USA, Cat. 10828-1-AP), cleaved PARP (Asp214) (Cell Signaling Technology, Danvers, MA, USA, Cat. 5625), $\beta$-actin (Cell Signaling Technology, Danvers, MA, USA, Cat. 8457), and $\beta$-tubulin D66 (Millipore Sigma, St. Louis, MO, USA, Cat. No. T0198). Following primary antibody incubation, goat anti-Mouse IgG $(\mathrm{H}+\mathrm{L})$ Superclonal ${ }^{\mathrm{TM}}$ Secondary Ab conjugated to HRP (Thermo Scientific, Rockford, IL, USA, Cat No. A28177) or Goat anti-Rabbit IgG (H + L) Superclonal ${ }^{\mathrm{TM}}$ Secondary Ab conjugated to HRP (Thermo Scientific, Rockford, IL, USA, Cat No. A27036) was used. Blots were developed with Amersham ${ }^{\mathrm{TM}}$ ECL $^{\mathrm{TM}}$ Prime Western Blotting Detection Reagent (GE Healthcare Life Sciences, Pittsburgh, PA, USA, Cat. No. RPN2232) and a G-Box Chemi system (Syngene USA, Frederick, MD, USA). Densitometry was performed using ImageJ software.

\section{9. $q P C R$}

Total RNA was extracted from SUM-159PT cells using a RNeasy ${ }^{\circledR}$ Mini Kit according to the manufacturer's instructions (Qiagen, Germantown, MD, USA, Cat. No. 74104). Following RNA isolation, cDNA was synthesized using a ProtoScript ${ }^{\circledR}$ II First Strand cDNA Synthesis Kit (NEB, Ipswich, MA, USA, Cat. No. E6560S). Then, $1 \mu \mathrm{g}$ of input RNA and oligo-dT primers were used according to the manufacturer's instructions. Finally, real-time PCR was performed using Luna ${ }^{\circledR}$ Universal qPCR Master Mix (NEB, Ipswich, MA, USA, Cat. No. M3003L), $1 \mu \mathrm{L}$ of cDNA, and the following forward and reverse primers: 1.) eIF4A1: 5' -AAGGCGTCATCGAGAGTAACT-3' and 5'-ATGTGGCCGTTTTCCCAGTC-3' 2.) c-MYC: $5^{\prime}$-CTTCTCTCCGTCCTCGGATTCT-3' and $5^{\prime}$-GAAGGTGATCCAGACTCTGACCTT-3' 3.) $\beta$-tubulin: $5^{\prime}$-TTGGCCAGATCTTTAGACCAGACAAC-3' and 5'-CCGTACCACATCCAGGACAGAATC- $3^{\prime}$. Real time data were analyzed using the $\triangle \triangle \mathrm{Ct}$ method with $\beta$-tubulin as the control. The values from DMSO treated SUM-159PT cells were then set to $100 \%$.

\subsection{Promoter Binding Analysis}

The promoter sequence $(-499$ to +100) for eIF4A (ENSG00000161960), eIF4E (ENSG00000151247), and eIF4G (ENSG00000114867) was obtained from the Eukaryotic Promoter Database (https://epd. epfl.ch//index.php). Putative transcription factor binding sites were predicted by PROMO (http: //alggen.lsi.upc.es/cgi-bin/promo_v3/promo/promoinit.cgi?dirDB=TF_8.3). Transcription factors were 
predicted within a dissimilarity margin less or equal than $15 \%$. Only human factors and sites were considered for analysis.

\subsection{1. iLINCS GSEA}

The Integrative Library of Integrated Network-Based Cellular Signatures (iLINCS) was used to obtain transcriptomic data of digoxin and bufalin treated MCF7 cells (http://www.ilincs.org/ilincs/). More specifically, LINCSCP_33452 (digoxin) and LINCSCP_33779 (bufalin) signatures were chosen for further analysis. MCF7 cells were treated with $10 \mu \mathrm{M}$ of each compound for 6 hours. Gene set enrichment analyses were performed by Enrichr. The "TF Perturbations Followed by Expression" gene-set library was selected for each compound.

\subsection{Rescue Experiments}

A total of $200 \mathrm{ng} /$ well of pcDNA3-eIF4A1 or pcDNA3-c-MYC was transfected into 293-HA-CXCR4 $(\mathrm{CGG})_{4}$ Luc2-tdTomato cells using Fugene 6 according to the manufacturer's instructions. Following transfection, each indicated amount of bufalin added to each well. Cells were incubated for $48 \mathrm{~h}$ before taking (CGG) 4 RFU and total protein (A595) readings.

\subsection{Cell Viability}

Cellular Viability was determined by using either Cell Titer-Glo (Promega, Madison, WI, USA, Cat. No. G7570) or Cell Titer-Blue (Promega, Madison, WI, USA, Cat. No. G8080) according to the manufacturer's instructions. Then, 3000 cells were plated in each well and were allowed to attach overnight. The next day, DMEM was replaced with drug-containing media and readings were taken $48 \mathrm{~h}$ later.

\subsection{Synergy Analysis}

The combination index of each drug combination was calculated by using the Chou-Talalay method of drug synergy and CompuSyn software (www.combosyn.com) [67]. Data were obtained from CompuSyn and graphed in Prism.

\subsection{Live-cell Cleaved Caspase 3 Staining}

Cleaved caspase 3/7 was stained in live cells by using the IncuCyte caspase 3/7 green reagent for Apoptosis (Essen BioScience, Ann Arbor, MI, USA, Cat. 4440) according to the manufacturer's instructions. Images were captured in an IncuCyte system (Essen Biosciences, Ann Arbor, MI, USA). Data were analyzed by calculating the total green object integrated intensity and \% confluence of each image using the IncuCyte software.

\subsection{Graph Preparation, Determination of $I_{50}$ Values, and Statistical Analysis}

All graphs, $\mathrm{IC}_{50}$ values, and statistical analysis was performed by using Prism 8 (GraphPad Software, San Diego, CA, USA).

\subsection{Patents}

Data in this manuscript have been included in a PCT patent application (60755-WO-PCT/D2019-32) in which Dayanidhi Raman, Amit K. Tiwari, and Cory M. Howard are listed as inventors.

\section{Conclusions}

In summary, we have identified cardiac glycosides as potential inhibitors of eIF4A1-mediated translation. This occurs in a narrow therapeutic window via decreases in c-MYC and subsequent eIF4A1 levels. Retrospective studies have indicated that digoxin does not increase mortality in breast 
cancer patients. It therefore may be a good candidate in combination with other eIF4F inhibitors for the treatment of triple-negative breast cancer.

Supplementary Materials: The following are available online at http:/www.mdpi.com/2072-6694/12/8/2169/s1, Figure S1: Cardiac glycosides modulate eIF4A expression levels through c-MYC; Figure S2: Uncropped blot figures.

Author Contributions: Conceptualization, C.M.H., A.K.T., and D.R.; methodology, C.M.H., D.T., and M.E.; investigation, C.M.H., D.T., and M.E.; writing—original draft preparation, C.M.H.; writing-review and editing, A.K.T. and D.R.; visualization, C.M.H.; supervision, D.R.; funding acquisition, D.R. All authors have read and agreed to the published version of the manuscript.

Funding: This research was funded by the National Institute of Health (NIH)/National Cancer Institute (R21CA202176 to DR), Ohio Cancer Research foundation (to DR), University of Toledo (F110796 start-up to DR), and the University of Toledo College of Graduate Studies (fellowship to CMH).

Acknowledgments: We thank Kevin Pan, Shi-He Liu, Nagalakshmi Nadiminty, and Nahum Sonenberg for sharing the materials outlined in Section 4. We also express our gratitude to Shruthi Santhanakrishnan who was a summer undergraduate student and shuttled the eIF4A1 open reading frame into pcDNA3.0.

Conflicts of Interest: The authors declare no conflict of interest.

\section{References}

1. Liedtke, C.; Mazouni, C.; Hess, K.R.; André, F.; Tordai, A.; Mejia, J.A.; Symmans, W.F.; Gonzalez-Angulo, A.M.; Hennessy, B.; Green, M.C.; et al. Response to Neoadjuvant Therapy and Long-Term Survival in Patients With Triple-Negative Breast Cancer. J. Clin. Oncol. 2008, 26, 1275-1281. [CrossRef] [PubMed]

2. Dent, R.; Trudeau, M.E.; Pritchard, K.I.; Hanna, W.; Kahn, H.K.; Sawka, C.A.; Lickley, L.A.; Rawlinson, E.; Sun, P.; Narod, S.A. Triple-Negative Breast Cancer: Clinical Features and Patterns of Recurrence. Clin. Cancer Res. 2007, 13, 4429-4434. [CrossRef] [PubMed]

3. Dent, R.; Hanna, W.M.; Trudeau, M.; Rawlinson, E.; Sun, P.; Narod, S.A. Pattern of metastatic spread in triple-negative breast cancer. Breast Cancer Res. Treat. 2008, 115, 423-428. [CrossRef] [PubMed]

4. Di Leo, A.; Desmedt, C.; Bartlett, J.M.S.; Piette, F.; Ejlertsen, B.; Pritchard, K.I.; Larsimont, D.; Poole, C.; Isola, J.; Earl, H.; et al. HER2 and TOP2A as predictive markers for anthracycline-containing chemotherapy regimens as adjuvant treatment of breast cancer: A meta-analysis of individual patient data. Lancet Oncol. 2011, 12, 1134-1142. [CrossRef]

5. Ellis, P.; Barrett-Lee, P.J.; Johnson, L.; Cameron, D.; Wardley, A.; O’Reilly, S.; Verrill, M.; Smith, I.; Yarnold, J.; Coleman, R.; et al. Sequential docetaxel as adjuvant chemotherapy for early breast cancer (TACT): An open-label, phase III, randomised controlled trial. Lancet 2009, 373, 1681-1692. [CrossRef]

6. Adams, S.; Loi, S.; Toppmeyer, D.; Cescon, D.; De Laurentiis, M.; Nanda, R.; Winer, E.; Mukai, H.; Tamura, K.; Armstrong, A.; et al. Pembrolizumab monotherapy for previously untreated, PD-L1-positive, metastatic triple-negative breast cancer: Cohort B of the phase II KEYNOTE-086 study. Ann. Oncol. 2019, 30, 405-411. [CrossRef]

7. Turner, N.; Telli, M.L.; Rugo, H.S.; Mailliez, A.; Ettl, J.; Grischke, E.-M.; Mina, L.A.; Balmaña, J.; Fasching, P.A.; Hurvitz, S.A.; et al. A Phase II Study of Talazoparib after Platinum or Cytotoxic Nonplatinum Regimens in Patients with Advanced Breast Cancer and Germline BRCA1/2 Mutations (ABRAZO). Clin. Cancer Res. 2018, 25, 2717-2724. [CrossRef]

8. Pelletier, J.; Sonenberg, N. The Organizing Principles of Eukaryotic Ribosome Recruitment. Annu. Rev. Biochem. 2019, 88, 307-335. [CrossRef]

9. Svitkin, Y.V.; Pause, A.; Haghighat, A.; Pyronnet, S.; Witherell, G.; Belsham, G.J.; Sonenberg, N. The requirement for eukaryotic initiation factor $4 \mathrm{~A}$ (eIF4A) in translation is in direct proportion to the degree of mRNA 5' secondary structure. RNA 2001, 7, 382-394. [CrossRef]

10. Pelletier, J.; Graff, J.; Ruggero, D.; Sonenberg, N. Targeting the eIF4F translation initiation complex: A critical nexus for cancer development. Cancer Res. 2015, 75, 250-263. [CrossRef]

11. Graff, J.R.; Konicek, B.W.; Vincent, T.M.; Lynch, R.L.; Monteith, D.; Weir, S.N.; Schwier, P.; Capen, A.; Goode, R.L.; Dowless, M.S.; et al. Therapeutic suppression of translation initiation factor eIF4E expression reduces tumor growth without toxicity. J. Clin. Investig. 2007, 117, 2638-2648. [CrossRef] [PubMed]

12. Nasr, Z.; Robert, F.; Porco, J.A.; Muller, W.J.; Pelletier, J. eIF4F suppression in breast cancer affects maintenance and progression. Oncogene 2012, 32, 861-871. [CrossRef] [PubMed] 
13. Modelska, A.; Turro, E.; Russell, R.; Beaton, J.; Sbarrato, T.; Spriggs, K.; Miller, J.; Graf, S.; Provenzano, E.; Blows, F.; et al. The malignant phenotype in breast cancer is driven by eIF4A1-mediated changes in the translational landscape. Cell Death Dis. 2015, 6, e1603. [CrossRef] [PubMed]

14. Sridharan, S.; Robeson, M.; Bastihalli-Tukaramrao, D.; Howard, C.M.; Subramaniyan, B.; Tilley, A.M.C.; Tiwari, A.K.; Raman, D. Targeting of the Eukaryotic Translation Initiation Factor 4A Against Breast Cancer Stemness. Front. Oncol. 2019, 9, 9. [CrossRef] [PubMed]

15. Moerke, N.J.; Aktas, H.; Chen, H.; Cantel, S.; Reibarkh, M.J.; Fahmy, A.; Gross, J.D.; Degterev, A.; Yuan, J.; Chorev, M.; et al. Small-Molecule Inhibition of the Interaction between the Translation Initiation Factors eIF4E and eIF4G. Cell 2007, 128, 257-267. [CrossRef] [PubMed]

16. Bordeleau, M.-E.; Matthews, J.; Wojnar, J.M.; Lindqvist, L.; Novac, O.; Jankowsky, E.; Sonenberg, N.; Northcote, P.; Teesdale-Spittle, P.; Pelletier, J. Stimulation of mammalian translation initiation factor eIF4A activity by a small molecule inhibitor of eukaryotic translation. Proc. Natl. Acad. Sci. USA 2005, 102, 10460-10465. [CrossRef]

17. Bordeleau, M.-E.; Mori, A.; Oberer, M.; Lindqvist, L.; Chard, L.S.; Higa, T.; Belsham, G.J.; Wagner, G.; Tanaka, J.; Pelletier, J. Functional characterization of IRESes by an inhibitor of the RNA helicase eIF4A. Nat. Chem. Biol. 2006, 2, 213-220. [CrossRef]

18. Iwasaki, S.; Floor, S.N.; Ingolia, N.T. Rocaglates convert DEAD-box protein eIF4A into a sequence-selective translational repressor. Nature 2016, 534, 558-561. [CrossRef]

19. Iwasaki, S.; Iwasaki, W.; Takahashi, M.; Sakamoto, A.; Watanabe, C.; Shichino, Y.; Floor, S.; Fujiwara, K.; Mito, M.; Dodo, K.; et al. The Translation Inhibitor Rocaglamide Targets a Bimolecular Cavity between eIF4A and Polypurine RNA. Mol. Cell 2019, 73, 738-748. [CrossRef]

20. Cencic, R.; Carrier, M.; Galicia-Vázquez, G.; Bordeleau, M.-E.; Sukarieh, R.; Bourdeau, A.; Brem, B.; Teodoro, J.G.; Greger, H.; Tremblay, M.L.; et al. Antitumor Activity and Mechanism of Action of the Cyclopenta[b]benzofuran, Silvestrol. PLoS ONE 2009, 4, e5223. [CrossRef]

21. Müller, D.; Shin, S.; De Rugy, T.G.; Samain, R.; Baer, R.; Strehaiano, M.; Masvidal-Sanz, L.; Guillermet-Guibert, J.; Jean, C.; Tsukumo, Y.; et al. eIF4A inhibition circumvents uncontrolled DNA replication mediated by 4E-BP1 loss in pancreatic cancer. JCI Insight 2019, 4. [CrossRef] [PubMed]

22. Zhang, W.; Chu, J.; Cyr, A.M.; Yueh, H.; Brown, L.E.; Wang, T.T.; Pelletier, J.; Porco, J.A. Intercepted Retro-Nazarov Reaction: Syntheses of Amidino-Rocaglate Derivatives and Their Biological Evaluation as eIF4A Inhibitors. J. Am. Chem. Soc. 2019, 141, 12891-12900. [CrossRef] [PubMed]

23. Chu, J.; Zhang, W.; Cencic, R.; Devine, W.G.; Beglov, D.; Henkel, T.; Brown, L.E.; Vajda, S.; Porco, J.A.; Pelletier, J. Amidino-Rocaglates: A Potent Class of eIF4A Inhibitors. Cell Chem. Boil. 2019, 26, 1586-1593. [CrossRef] [PubMed]

24. Ernst, J.T.; Thompson, P.A.; Nilewski, C.; Sprengeler, P.A.; Sperry, S.; Packard, G.; Michels, T.; Xiang, A.; Tran, C.; Wegerski, C.J.; et al. Design of Development Candidate eFT226, a First in Class Inhibitor of Eukaryotic Initiation Factor 4A RNA Helicase. J. Med. Chem. 2020, 63, 5879-5955. [CrossRef] [PubMed]

25. Ashburn, T.T.; Thor, K.B. Drug repositioning: Identifying and developing new uses for existing drugs. Nat. Rev. Drug Discov. 2004, 3, 673-683. [CrossRef]

26. Holmes, M.D.; Chen, W.Y. Hiding in plain view: The potential for commonly used drugs to reduce breast cancer mortality. Breast Cancer Res. 2012, 14, 216. [CrossRef]

27. Wolfe, A.L.; Singh, K.; Zhong, Y.; Drewe, P.; Rajasekhar, V.K.; Sanghvi, V.R.; Mavrakis, K.J.; Jiang, M.; Roderick, J.E.; Van Der Meulen, J.; et al. RNA G-quadruplexes cause eIF4A-dependent oncogene translation in cancer. Nature 2014, 513, 65-70. [CrossRef]

28. Waldron, J.A.; Raza, F.; Le Quesne, J. eIF4A alleviates the translational repression mediated by classical secondary structures more than by G-quadruplexes. Nucleic Acids Res. 2018, 46, 3075-3087. [CrossRef]

29. Waldron, J.A.; Tack, D.C.; Ritchey, L.E.; Gillen, S.L.; Wilczynska, A.; Turro, E.; Bevilacqua, P.C.; Assmann, S.M.; Bushell, M.; Le Quesne, J. mRNA structural elements immediately upstream of the start codon dictate dependence upon eIF4A helicase activity. Genome Boil. 2019, 20, 300-323. [CrossRef]

30. Prassas, I.; Diamandis, E.P. Novel therapeutic applications of cardiac glycosides. Nat. Rev. Drug Discov. 2008, 7, 926-935. [CrossRef]

31. Samanta, D.; Gilkes, D.M.; Chaturvedi, P.; Xiang, L.; Semenza, G.L. Hypoxia-inducible factors are required for chemotherapy resistance of breast cancer stem cells. Proc. Natl. Acad. Sci. USA 2014, 111, E5429-E5438. [CrossRef] [PubMed] 
32. Wang, Y.; Lonard, D.M.; Yu, Y.; Chow, D.-C.; Palzkill, T.G.; Wang, J.; Qi, R.; Matzuk, A.J.; Song, X.; Madoux, F.; et al. Bufalin is a potent small-molecule inhibitor of the steroid receptor coactivators SRC-3 and SRC-1. Cancer Res. 2014, 74, 1506-1517. [CrossRef] [PubMed]

33. Xie, C.-M.; Lin, X.-T.; Wu, D.; Tan, Y.; Cheng, C.; Zhang, J. Cardiac glycoside bufalin blocks cancer cell growth by inhibition of Aurora A and Aurora B activation via PI3K-Akt pathway. Oncotarget 2018, 9, 13783-13795. [CrossRef] [PubMed]

34. Perne, A.; Muellner, M.K.; Steinrueck, M.; Craig-Mueller, N.; Mayerhofer, J.; Schwarzinger, I.; Sloane, M.; Uras, I.Z.; Hoermann, G.; Nijman, S.M.B.; et al. Cardiac Glycosides Induce Cell Death in Human Cells by Inhibiting General Protein Synthesis. PLoS ONE 2009, 4, e8292. [CrossRef]

35. Ouyang, X.; Han, S.N.; Zhang, J.Y.; Dioletis, E.; Nemeth, B.T.; Pacher, P.; Feng, D.; Bataller, R.; Cabezas, J.; Starkel, P.; et al. Digoxin Suppresses Pyruvate Kinase M2-Promoted HIF-1alpha Transactivation in Steatohepatitis. Cell Metab. 2018, 27, 339-350. [CrossRef]

36. Karas, K.; Salkowska, A.; Sobalska-Kwapis, M.; Walczak-Drzewiecka, A.; Strapagiel, D.; Dastych, J.; Bachorz, R.A.; Ratajewski, M. Digoxin, an Overlooked Agonist of RORgamma/RORgammaT. Front. Pharmacol. 2018, 9, 1460. [CrossRef]

37. Didiot, M.-C.; Hewett, J.; Varin, T.; Freuler, F.; Selinger, D.; Nick, H.; Reinhardt, J.; Buckler, A.; Myer, V.; Schuffenhauer, A.; et al. Identification of Cardiac Glycoside Molecules as Inhibitors of c-Myc IRES-Mediated Translation. J. Biomol. Screen. 2013, 18, 407-419. [CrossRef]

38. Steinberger, J.; Robert, F.; Hallé, M.; Williams, D.E.; Cencic, R.; Sawhney, N.; Pelletier, D.; Williams, P.; Igarashi, Y.; Porco, J.A.; et al. Tracing MYC Expression for Small Molecule Discovery. Cell Chem. Boil. 2019, 26, 699-710. [CrossRef]

39. Polunovsky, V.A.; Rosenwald, I.B.; Tan, A.T.; White, J.; Chiang, L.; Sonenberg, N.; Bitterman, P.B. Translational control of programmed cell death: Eukaryotic translation initiation factor 4E blocks apoptosis in growth-factor-restricted fibroblasts with physiologically expressed or deregulated Myc. Mol. Cell. Boil. 1996, 16, 6573-6581. [CrossRef]

40. Ruggero, D.; Montanaro, L.; Ma, L.; Xu, W.; Londei, P.; Cordon-Cardo, C.; Pandolfi, P.P. The translation factor eIF-4E promotes tumor formation and cooperates with c-Myc in lymphomagenesis. Nat. Med. 2004, 10, 484-486. [CrossRef]

41. Lin, C.-J.; Cencic, R.; Mills, J.R.; Robert, F.; Pelletier, J. c-Myc and eIF4F Are Components of a Feedforward Loop that Links Transcription and Translation. Cancer Res. 2008, 68, 5326-5334. [CrossRef] [PubMed]

42. Hart, J.R.; Garner, A.L.; Yu, J.; Ito, Y.; Sun, M.; Ueno, L.; Rhee, J.-K.; Baksh, M.M.; Stefan, E.; Hartl, M.; et al. Inhibitor of MYC identified in a Krohnke pyridine library. Proc. Natl. Acad. Sci. USA 2014, 111, 12556-12561. [CrossRef] [PubMed]

43. Chen, H.; Liu, H.; Qing, G. Targeting oncogenic Myc as a strategy for cancer treatment. Signal Transduct. Target. Ther. 2018, 3, 5. [CrossRef] [PubMed]

44. Karasneh, R.A.; Murray, L.J.; McMenamin, Ú.; Hughes, C.M.; Cardwell, C.R. Digoxin use after diagnosis of breast cancer and survival: A population-based cohort study. Breast Cancer Res. Treat. 2015, 151, 661-669. [CrossRef] [PubMed]

45. Clifford, R.J.; Kaplan, J.H. Human Breast Tumor Cells Are More Resistant to Cardiac Glycoside Toxicity Than Non-Tumorigenic Breast Cells. PLoS ONE 2013, 8, e84306. [CrossRef] [PubMed]

46. Tan, A.; Bitterman, P.B.; Sonenberg, N.; Peterson, M.; Polunovsky, V. Inhibition of Myc-dependent apoptosis by eukaryotic translation initiation factor $4 \mathrm{E}$ requires cyclin D1. Oncogene 2000, 19, 1437-1447. [CrossRef]

47. Simpson, C.D.; Mawji, I.A.; Anyiwe, K.; Williams, M.A.; Wang, X.; Venugopal, A.L.; Gronda, M.; Hurren, R.; Cheng, S.; Serra, S.; et al. Inhibition of the Sodium Potassium Adenosine Triphosphatase Pump Sensitizes Cancer Cells to Anoikis and Prevents Distant Tumor Formation. Cancer Res. 2009, 69, 2739-2747. [CrossRef]

48. Lin, S.-Y.; Chang, H.-H.; Lai, Y.-H.; Lin, C.-H.; Chen, M.-H.; Chang, G.-C.; Tsai, M.-F.; Chen, J.J.W. Digoxin Suppresses Tumor Malignancy through Inhibiting Multiple Src-Related Signaling Pathways in Non-Small Cell Lung Cancer. PLoS ONE 2015, 10, e0123305. [CrossRef]

49. Wang, Z.; Zheng, M.; Li, Z.; Li, R.; Jia, L.; Xiong, X.; Southall, N.; Wang, S.; Xia, M.; Austin, C.P.; et al. Cardiac glycosides inhibit 553 synthesis by a mechanism relieved by Src or MAPK inhibition. Cancer Res. 2009, 69, 6556-6564. [CrossRef] 
50. Triana-Martínez, F.; Picallos-Rabina, P.; Da Silva-Álvarez, S.; Pietrocola, F.; Llanos, S.; Rodilla, V.; Soprano, E.; Pedrosa, P.; Ferreirós, A.; Barradas, M.; et al. Identification and characterization of Cardiac Glycosides as senolytic compounds. Nat. Commun. 2019, 10,1-12. [CrossRef]

51. Schito, L.; Rey, S.; Tafani, M.; Zhang, H.; Wong, C.C.-L.; Russo, A.; Russo, M.A.; Semenza, G.L. Hypoxia-inducible factor 1-dependent expression of platelet-derived growth factor B promotes lymphatic metastasis of hypoxic breast cancer cells. Proc. Natl. Acad. Sci. USA 2012, 109, E2707-E2716. [CrossRef] [PubMed]

52. Liu, X.; Zhou, Y.; Peng, J.; Xie, B.; Shou, Q.; Wang, J. Silencing c-Myc Enhances the Antitumor Activity of Bufalin by Suppressing the HIF-1 $\alpha /$ SDF-1/CXCR4 Pathway in Pancreatic Cancer Cells. Front. Pharmacol. 2020, 11, 495. [CrossRef] [PubMed]

53. Schmidt, E.V. The role of c-myc in regulation of translation initiation. Oncogene 2004, 23, 3217-3221. [CrossRef] [PubMed]

54. Stoelzle, T.; Schwarb, P.; Trumpp, A.; Hynes, N.E. c-Myc affects mRNA translation, cell proliferation and progenitor cell function in the mammary gland. BMC Boil. 2009, 7, 63. [CrossRef]

55. Ruggero, D. The role of Myc-induced protein synthesis in cancer. Cancer Res. 2009, 69, 8839-8843. [CrossRef] [PubMed]

56. Lazaris-Karatzas, A.; Sonenberg, N. The mRNA 5' cap-binding protein, eIF-4E, cooperates with v-myc or E1A in the transformation of primary rodent fibroblasts. Mol. Cell. Boil. 1992, 12, 1234-1238. [CrossRef]

57. Lin, C.-J.; Nasr, Z.; Premsrirut, P.K.; Porco, J.A.; Hippo, Y.; Lowe, S.W.; Pelletier, J. Targeting Synthetic Lethal Interactions between Myc and the eIF4F Complex Impedes Tumorigenesis. Cell Rep. 2012, 1, 325-333. [CrossRef]

58. Pourdehnad, M.; Truitt, M.L.; Siddiqi, I.N.; Ducker, G.S.; Shokat, K.M.; Ruggero, D. Myc and mTOR converge on a common node in protein synthesis control that confers synthetic lethality in Myc-driven cancers. Proc. Natl. Acad. Sci. USA 2013, 110, 11988-11993. [CrossRef]

59. Xu, Y.; Poggio, M.; Jin, H.Y.; Shi, Z.; Forester, C.M.; Wang, Y.; Stumpf, C.R.; Xue, L.; Devericks, E.; So, L.; et al. Translation control of the immune checkpoint in cancer and its therapeutic targeting. Nat. Med. 2019, 25, 301-311. [CrossRef]

60. Tameire, F.; Verginadis, I.I.; Leli, N.M.; Polte, C.; Conn, C.S.; Ojha, R.; Salinas, C.S.; Chinga, F.; Monroy, A.M.; $\mathrm{Fu}, \mathrm{W}$; et al. ATF4 couples MYC-dependent translational activity to bioenergetic demands during tumour progression. Nat. Cell. Biol. 2019, 21, 889-899. [CrossRef]

61. McBryan, J.; Theissen, S.M.; Byrne, C.; Hughes, E.; Cocchiglia, S.; Sande, S.; O'Hara, J.; Tibbitts, P.; Hill, A.D.; Young, L. Metastatic Progression with Resistance to Aromatase Inhibitors Is Driven by the Steroid Receptor Coactivator SRC-1. Cancer Res. 2011, 72, 548-559. [CrossRef] [PubMed]

62. Osman, M.H.; Farrag, E.; Selim, M.; Hasanine, A.; Selim, A.; Osman, M.S. Cardiac glycosides use and the risk and mortality of cancer; systematic review and meta-analysis of observational studies. PLoS ONE 2017, 12, e0178611. [CrossRef] [PubMed]

63. Biggar, R.J.; Wohlfahrt, J.; Oudin, A.; Hjuler, T.; Melbye, M. Digoxin Use and the Risk of Breast Cancer in Women. J. Clin. Oncol. 2011, 29, 2165-2170. [CrossRef] [PubMed]

64. Duvall-Noelle, N.; Karwandyar, A.; Richmond, A.; Raman, D. LASP-1: A nuclear hub for the UHRF1-DNMT1-G9a-Snail1 complex. Oncogene 2015, 35, 1122-1133. [CrossRef]

65. Johnson, R.W.; Nguyen, M.P.; Padalecki, S.S.; Grubbs, B.G.; Merkel, A.R.; Oyajobi, B.O.; Matrisian, L.M.; Mundy, G.R.; Sterling, J.A. TGF-beta promotion of Gli2-induced expression of parathyroid hormone-related protein, an important osteolytic factor in bone metastasis, is independent of canonical Hedgehog signaling. Cancer Res. 2010, 71, 822-831. [CrossRef]

66. Howard, C.M.; Bearss, N.; Subramaniyan, B.; Tilley, A.; Sridharan, S.; Villa, N.; Fraser, C.S.; Raman, D. The CXCR4-LASP1-eIF4F Axis Promotes Translation of Oncogenic Proteins in Triple-Negative Breast Cancer Cells. Front. Oncol. 2019, 9, 284. [CrossRef]

67. Chou, T.-C. Drug Combination Studies and Their Synergy Quantification Using the Chou-Talalay Method. Cancer Res. 2010, 70, 440-446. [CrossRef]

(C) 2020 by the authors. Licensee MDPI, Basel, Switzerland. This article is an open access article distributed under the terms and conditions of the Creative Commons Attribution (CC BY) license (http://creativecommons.org/licenses/by/4.0/). 